\title{
CLINICAL PROFILE OF ACUTE VIRAL HEPATITIS- A AND FACTORS ASSOCIATED WITH BAD OUTCOME
}

\author{
Shameer Ananthamangalath ${ }^{1}$, Mohamed Shaan²
}

1 Junior Resident, Department of General Medicine, Government Medical College, Kozhikode.

${ }^{2}$ Associate Professor, Department of General Medicine, Government Medical College, Kozhikode.

\section{BACKGROUND}

\section{ABSTRACT}

Hepatitis A is the most common cause of acute viral hepatitis. There has been an increase in the disease burden in many parts of the world, along with more complications and many atypical manifestations. The main aim of study is to identify the clinical profile, atypical manifestation and risk factors associated with bad outcome.

\section{MATERIAL AND METHODS}

A Prospective observational study was conducted on 100 consecutive patients who attended the Medicine Department at Calicut Medical College. Patients were kept under follow up for three months. Clinical evaluations and focused investigations were conducted on those patients.

\section{RESULTS}

Most of the patients were between 13 to 32 years. Thrombocytopenia, transverse myelitis, arthralgias, pancreatitis and acute kidney injury were some of the atypical manifestations. Two patients died.

\section{CONCLUSION}

There was no correlation between SGPT levels and complications. Prior NSAID \& alcohol intake is associated with adverse outcome.

\section{KEYWORDS}

Acute Viral Hepatitis A, NSAIDS, Hepatic encephalopathy.

HOW TO CITE THIS ARTICLE: Ananthamangalath S, Shaan M. Clinical profile of acute viral hepatitis-A and factors associated with bad outcome. J. Evolution Med. Dent. Sci. 2018;7(07):876-880, DOI: 10.14260/jemds/2018/200

\section{BACKGROUND}

Hepatitis A virus (HAV) is a cause of acute liver inflammation or hepatitis. It can cause relapsing signs and symptoms but not a chronic infection. It belongs to the family Picornaviridae and the genus Hepatovirus. It has characteristics of the enteroviruses. Viral transmission occurs in a faecal-oral fashion. An estimated 1.5 million clinical cases of hepatitis A virus infection occur in the world each year 1 . Hepatitis $A$ viral infection can be super infected or co infected with other viral infections and it is one of the most widespread liver infections in the world, particularly in developing countries. The virus is more prevalent in areas with poor sanitary conditions. The most common source of hepatitis A is direct person-to-person exposure and, to a lesser extent, direct faecal contamination of food or water. ${ }^{2}$ Consumption of raw or partially cooked shellfish raised in contaminated waterways is an uncommon but possible source of hepatitis A.

The clinical manifestations of HAV infection are widely variable, depending on the host response. They range from silent infection and spontaneous resolution to fulminant hepatic failure.

'Financial or Other Competing Interest': None.

Submission 07-01-2018, Peer Review 31-01-2018,

Acceptance 06-02-2018, Published 12-02-2018.

Corresponding Author:

Dr. Mohamed Shaan,

Maskan, 5/1986 B,

K. P. Chandran Road,

P. O. Puthiyara

Calicut-673004, Kerala.

E-mail: shaanmohamed77@gmail.com

DOI: $10.14260 /$ jemds $/ 2018 / 200$
The incubation period of HAV ranges from 15-49 days (mean 25 days). The prodromal phase is characterized by nonspecific symptoms such as fatigue, weakness, anorexia, nausea, vomiting, abdominal pain and fever. Headache, arthralgias, myalgias, rash, or diarrhoea can follow. Jaundice begins within 1-2 weeks from the onset of the prodrome. Extrahepatic manifestations are uncommon and include a leukocytoclastic vasculitis, glomerulonephritis, arthritis, immune complex disease, toxic epidermal necrolysis, myocarditis, optic neuritis, transverse myelitis, polyneuritis, thrombocytopenia, aplastic anaemia, and red cell aplasia ${ }^{3}$ The course of hepatitis A infection is benign in most of those infected. It is occasionally severe, or fulminant in adults, particularly in those with chronic liver disease.

After initial studies on the clinical features of the disease and subsequent development of safe and effective vaccines in the early 1990s, research on acute hepatitis A faded away. However, according to improvements in health sanitation and living conditions, changes in the epidemiology of HAV have paradoxically increased the disease burden in many regions of the world, especially in adult population and complications and atypical manifestations of acute viral hepatitis A are also more prevalent in adult population.

\section{Aims and Objectives}

1. To study the clinical profile of acute viral hepatitis A.

2. To study the atypical manifestations of acute viral hepatitis A.

3. To study the risk factors associated with adverse outcome. 


\section{MATERIALS AND METHODS}

\section{Study Design}

Prospective hospital based observational study.

\section{The Centre and Period of Study}

Government Medical College, Kozhikode. The study was conducted between January 2014 and June 2015.

\section{Study Population}

Patients admitted in department of general medicine wards, satisfying inclusion criteria.

\section{Inclusion Criteria}

Patients with clinical and biochemical profile suggestive of acute viral hepatitis with positive serological viral marker for hepatitis A-IgM HAV.

\section{Exclusion Criteria}

- $\quad$ Patients with serology positive for HbsAg \& IgM anti HCV.

- Chronic liver disease or USG abdomen showing features of chronic liver disease.

- Chronic kidney disease or USG showing features suggestive of chronic kidney disease 30.

- Patients on hepatotoxic drugs.

- Patients with serious co morbid illness.

\section{Sample Size}

Study will include a total of 100 subjects meeting the inclusion criteria.

\section{Data Collection}

Computer data sheet for demographics, direct interview and questionnaires and detailed clinical examinations and relevant laboratory investigations.

It is a prospective hospital based observational study. Total of 100 consecutive patients admitted due to acute viral hepatitis in medical wards of Government medical college Kozhikode between Jan 2014 to June 2015 were enrolled for the study. Patients were selected according to inclusion and exclusion criteria.

All patients underwent a detailed history, daily clinical examination after obtaining their informed consent. Haematological and biochemical investigations were performed on all patients including complete blood counts, ESR, renal and liver function tests, serum electrolytes, blood sugar, urine examination, ECG, PT-INR, APTT, IgM-HAV, HBsAg, Anti-HCV. Radiological investigation include USG abdomen to rule out underlying chronic liver or kidney disease.

All patients were managed symptomatically and complications were managed according to standard treatment protocol of the hospital. All patients are followed up till 3 months or liver enzymes become normal, whichever is earlier.

\section{Statistical Analysis}

The results were entered into a Microsoft Excel sheet and then analysed using the SPSS statistical software version 20 and conclusions drawn accordingly. The statistical significance of different variables was calculated on the basis of Chi - Square test.

\section{Ethical Concerns}

Strict confidentiality was maintained regarding the identity of each individual patient. The patients were given option to participate in the study or not to participate with the help of an informed consent form. The patients were neither be exposed to any invasive procedures nor be given drugs as part of the study.

\section{RESULTS}

Of the 100 patients, $44 \%$ belonged to the $13-22$ years age group, $47 \%$ belonged to the $23-32$ years age group, maximum age observed was 56 years and minimum age observed was 13 years with an average of $23.6 \pm 8.3$ years (Fig. 1 ).

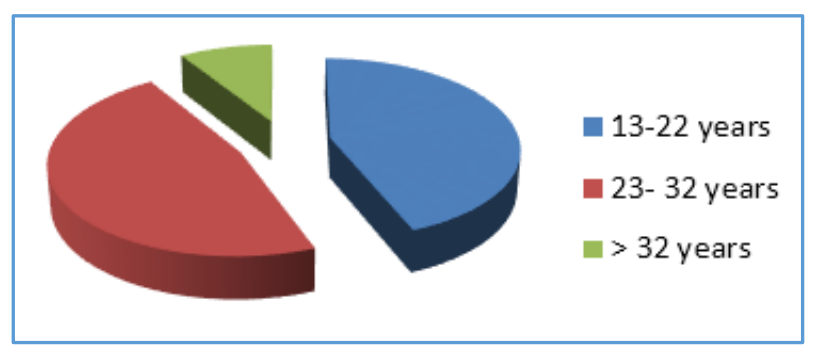

Figure 1. Age distribution

Out of 100 patients $96 \%$ had documented fever and $4 \%$ presented without fever and $38 \%$ had continuing fever even after the onset of clinical jaundice. Thus hepatitis A may present as long duration fever. Out of 100 patients, 32 patients had thrombocytopenia, 9 patients had arthralgias /arthritis, 7 patients had AKI, 5 patients had pancreatitis, 4 patients had rash, one patient had acute transverse myelitis and thrombocytosis. Out of 100 patients $12 \%$ of the patients had hepatic encephalopathy, $6 \%$ of the patients had symptomatic bleeding, $7 \%$ of the patients had ascites, $5 \%$ of the patients had pancreatitis, $16 \%$ of patients had cholestatic hepatitis, $7 \%$ of patients developed AKI and one patient had transverse myelitis. (Fig. 2). Out of these 2 patients expired. $67 \%$ of the patients recovered without any complications, $31 \%$ had at least one complication.(Fig. 3).

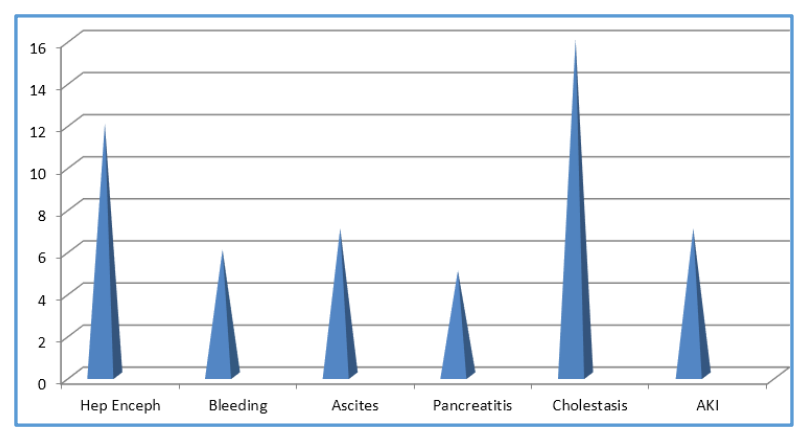

Figure 2. Clinical Presentation

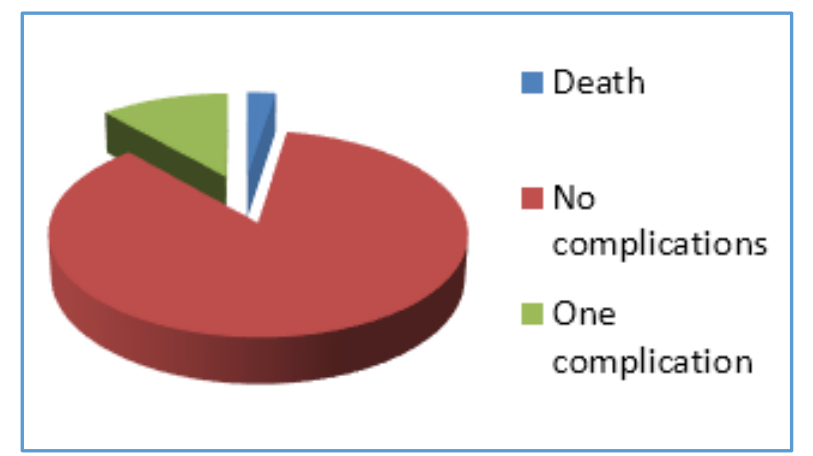

Figure 3. ComplicationsFactors Associated with Bad Outcome 
In this study, the median age of the patients was $23.6 \pm 8.3$, and substantial numbers of patients were below $40 \mathrm{yr}$. We compared the severity of hepatitis between the groups of the patients younger and older than $40 \mathrm{yr}$. The clinical manifestations including complications and laboratory data showed that the clinical course in terms of hepatic dysfunction and renal complication were worse in the group of the patients between 23-32 years.

Presence of alcoholism and bad outcome is closely related. Among alcoholic patients $69.2 \%$ had at least one complication with a statistically significant $p$ value of 0.003 . Most common complication noted was fulminant hepatic failure followed by acute pancreatitis.

\section{Alcohol and Outcome}

\begin{tabular}{|c|c|c|c|c|c|}
\hline Alcohol & $\begin{array}{c}\text { Re } \\
\text { covered }\end{array}$ & $\begin{array}{c}\text { Re } \\
\text { covered }\end{array}$ & $\begin{array}{c}\text { Compli- } \\
\text { cated }\end{array}$ & $\begin{array}{c}\text { Compli- } \\
\text { cated }\end{array}$ & Total \\
\hline & Count & Percent & Count & Percent & \\
\hline Yes & 4 & 30.8 & 9 & 69.2 & 13 \\
\hline No & 63 & 72.4 & 24 & 27.6 & 87 \\
\hline Total & $\mathbf{6 7}$ & & $\mathbf{3 3}$ & & $\mathbf{1 0 0}$ \\
\hline \multicolumn{5}{|c|}{ Table 1. Association of presence of alcohol } \\
intake and outcome
\end{tabular}

$\mathrm{X} 2=8.871 \mathrm{P}=0.003$.

NSAID intake also had a significant relation with adverse outcome ( $p$ 0.015) and among patients who took NSAID $54.5 \%$ had complications compared to non NSAID group, who had a complication rate of $26.9 \%$. Most common complication noted in NSAID group was fulminant hepatic failure with symptomatic bleeding.

\begin{tabular}{|c|c|c|c|c|c|}
\hline $\begin{array}{c}\text { NSAID } \\
\text { intake }\end{array}$ & $\begin{array}{c}\text { Re- } \\
\text { covered }\end{array}$ & $\begin{array}{c}\text { Re- } \\
\text { covered }\end{array}$ & $\begin{array}{c}\text { Compli- } \\
\text { cated }\end{array}$ & $\begin{array}{c}\text { Compli- } \\
\text { cated }\end{array}$ & Total \\
\hline & Count & Percent & Count & Percent & \\
\hline Yes & 10 & 45.5 & 12 & 54.5 & 22 \\
\hline No & 57 & 73.1 & 21 & 26.9 & 78 \\
\hline Total & $\mathbf{6 7}$ & & $\mathbf{3 3}$ & & $\mathbf{1 0 0}$ \\
\hline
\end{tabular}

Table 2. Association of NSAID intake and adverse outcome

\section{$\mathrm{X} 2=5.922 \mathrm{P}=0.015$}

There was no statistical correlation was found between WBC count and adverse outcome $(\mathrm{p}=0.625)$ and even though $32 \%$ of the patients had thrombocytopenia, no significant relation was found between platelet count and adverse outcome ( $\mathrm{p}=0.114)$. Regarding SGPT value and outcome, $41 \%$ peak SGPT values was within 2001-4000, 32\% within 40018000, $17 \%$ within $1001-2000$, $6 \%$ within $501-1000,2 \%$ below $<500$ and $2 \%>8000$ IU. Maximum value of SGPT observed was $14000 \mathrm{IU}$ and minimum value was $350 \mathrm{IU}$. No significant correlation was found between SGPT value and adverse outcome. $(\mathrm{p}=0.357)$.

Intake of indigenous medication was found to be associated with adverse outcome and it was associated with development of cholestatic hepatitis. Out of 100 patients, 25 had taken indigenous medication for the treatment of hepatitis A. It was in powder and tablet form and content of the medication was not known. Among the patients who took indigenous medication $48 \%$ developed cholestatic hepatitis with significant statistical correlation $(\mathrm{P}<0.001)$.

\begin{tabular}{|c|c|c|c|c|}
\hline $\begin{array}{c}\text { Indigenous } \\
\text { medications }\end{array}$ & $\begin{array}{c}\text { Cho- } \\
\text { lestasis }\end{array}$ & $\begin{array}{c}\text { Cho- } \\
\text { lestasis }\end{array}$ & $\begin{array}{c}\text { No } \\
\text { Cholestasis }\end{array}$ & $\begin{array}{c}\text { No } \\
\text { Cholestasis }\end{array}$ \\
\hline Yes & 12 & 48 & 13 & 52 \\
\hline No & 4 & 5.3 & 71 & 94.7 \\
\hline Total & $\mathbf{1 6}$ & & 33 & \\
\hline \multicolumn{5}{|c|}{ Table 3. Association of intake of indigenous medication } \\
and prolonged cholestasis \\
\hline
\end{tabular}

$\mathrm{X} 2=25.397 \mathrm{P}<0.001$

Out of 100 patients, 12 patients developed fulminant hepatic failure. Out of these 10 patients recovered and 2 patients expired. From the recovered patients, nine patients had grade 1-2 hepatic encephalopathy.

\section{DISCUSSION}

Acute hepatitis A is a common viral infection found throughout the world and is spread principally via faeco-oral route. The clinical spectrum of acute hepatitis A virus (HAV) infection is varied and includes silent infection detected only by viral serologic testing, subclinical infection revealed by abnormal liver tests, clinically apparent hepatitis, and rarely, fulminant hepatitis, which is associated with coma and occasionally death. ${ }^{4}$ While most infants and children have silent or subclinical infections, the majority of adults develop symptoms and signs of acute disease. Atypical manifestations such as relapse, cholestasis, rash, and arthralgia also have been described in patients with hepatitis $\mathrm{A}$, but the pathophysiology of these phenomena has not been elucidated.

One hundred patients with clinical and biochemical profile suggestive of acute viral hepatitis A and satisfying inclusion criteria were studied from January 2014 to June 2015. Of the 100 patients, $44 \%$ belonged to the $13-22$ years age group, $47 \%$ belonged to the 23-32 years age group, $6 \%$ belonged to the 33-42 years age group and 3\% belonged to the 53-62 years age group. Maximum age observed was 56 years and minimum age observed was 13 years with an average of $23.6 \pm 8.3$ years. So, most of the patients were belonging to younger adult group (23-32 years) indicates that North Kerala is moderately prevalent for hepatitis A. This is the most active group of total populations and may be related to life style habits like food intake from outside and also most of the older adults have serologically positive antibodies against hepatitis $\mathrm{A}$, indicating that subclinical infections are common. In Koffet al 5 study, surveys in many communities showed a high prevalence of antibodies to hepatitis A virus (HAV) in people over the age of 50 years. However, few of that age can recall a previous episode of hepatitis, indicating that subclinical infections are common. The outcome of infection with HAV depends on the age at which infection occurs and, perhaps, the infectious dose. HAV infection tends to be asymptomatic in children $<5$ years of age and imparts lifelong immunity. Thus, in high prevalence areas where most of the population is exposed at a very young age and develops immunity without symptoms, we expect to see fewer symptomatic cases. If exposure to infection occurs for the first time at older ages, patients are more likely to develop symptomatic disease. Our patients were mostly from low economic background but still turned out to be not immune to hepatitis A infection. Our study implies that hepatitis A still remains an important cause of acute viral hepatitis in adults, 
at least in North Kerala. In view of this, a recommendation for mass vaccination against hepatitis A needs to be considered and debated.

Of the 100 patients, 69\% were males and 31\% were females. This also may be related to difference in lifestyle habits among males and females like food intake from outside. Out of 100 patients, $96 \%$ had documented fever and $4 \%$ presented without fever. Of these, $31 \%$ of the patients had 1-3 days of fever, $52 \%$ had $4-6$ days of fever, $13 \%$ had prolonged fever $>6$ days and $4 \%$ had no fever. Maximum duration of fever observed was 14 days for 5 patients. Out of total 100 sample patients, $38 \%$ had continuing fever even after the onset of clinical jaundice. Thus hepatitis A may present as long duration fever.

Of the 100 patients, 31 patients had significant nausea/vomiting and anorexia requiring anti-emetics and intravenous fluids. $40 \%$ had a definite history of contact in the form of clustering of cases, either in family members or in locality. 6

A multicentre study conducted by Kwon, So Young et $\mathrm{al}^{7}$ in Korea showed fever in $71.5 \%$ with an average duration of $5 \pm 2$ days. Out of 100 patients, $13 \%$ had definite history of alcohol intake at least once in a week, 22 patients had received NSAID prior to the admission and 25 had history of intake of indigenous medication.

Out of 100 patients, 32 patients had thrombocytopenia, 9 patients had arthralgia/arthritis, 7 patients had AKI, 5 patients had pancreatitis, 4 patients had rash, acute transverse myelitis and thrombocytosis for one patient each. Jung YM et al. ${ }^{8}$ study showed $4.7 \%$ pancreatitis and $1.5 \%$ AKI as atypical manifestations. Kwon SY, et al. ${ }^{7}$ study showed $17.8 \%$ of arthralgia, $4.4 \%$ skin rash and $2.7 \%$ of AKI as atypical manifestations.

Out of 100 patients, 80 patients had normal WBC count between $4000-11000$ cells $/ \mathrm{mm} 3,13$ patients had low WBC count below 4000 cells/mm3 and 7 patients had high WBC count more than 11000 cells/mm3 with a mean value of 5604 \pm 1809 . Kwon SY, et $\mathrm{al}^{7}$ study showed mean WBC count of $5101 \pm 2509$ cells $/ \mathrm{mm} 3.47 \%$ had platelet count $>2$ lakhs, $21 \%$ within $1.5-1.9$ lakhs, $20 \%$ within $1-1.49$ lakhs, $12 \%$ had platelet count below 1 lakh with a mean value of $1.89 \pm 0.68$. Out of these 32 patients had thrombocytopenia (platelet count $<1.5$ lakh). Shenoy R, et al. study showed mean platelet value of $1.77=0.84 .9$

Out of 100 patients, 4 patients had microscopic haematuria. Out of 100 patients, $56 \%$ had peak total bilirubin value $<5 \mathrm{mg} / \mathrm{dl}, 33 \%$ belonging to $5.1-10 \mathrm{mg} / \mathrm{dl}, 4 \% 10.1-15$ $\mathrm{mg} / \mathrm{dl}$ and $7 \%$ of patient's bilirubin was $>15 \mathrm{mg} / \mathrm{dl}$. Mean peak total bilirubin was $6.3 \pm 2.8$. This was consistent with mean peak total bilirubin value of Kwon SY, et al. study, which was $7.3 \pm 5.3$.

Out of 100 patients, $41 \%$ peak SGPT values was within 2001-4000, 32\% within 4001-8000, 17\% within 1001-2000, $6 \%$ within $501-1000,2 \%$ below $<500$ and $2 \%>8000$ IU. Mean peak SGPT value was $2858 \pm 812$, this was consistent with mean peak SGPT value of Kwon SY, et al. study, which was $2963 \pm 542$.

Out of 100 patients, $12 \%$ of the patients had hepatic encephalopathy, $6 \%$ of the patients had symptomatic bleeding, $7 \%$ of the patients had ascites, $5 \%$ of the patients had pancreatitis, $16 \%$ of patients had cholestatic hepatitis, $7 \%$ of patients developed $\mathrm{AKI}$ and one patient had transverse myelitis.

Out of these, 2 patients expired. $67 \%$ of the patients recovered without any complications, $31 \%$ had at least one complication. Korean study by Kwon SY, et al. showed $0.47 \%$ of mortality and $1.92 \%$ of cholestatic hepatitis and $0.91 \%$ fulminant hepatic failure. In our study all complications rate and mortality are high, may be because being a tertiary care centre most of the complicated cases are referred from periphery.

As age advances, the rate of complications is not increasing in our study and Chi square test shows that age and adverse outcome is not statistically significantly related (p 0.295). This is probably due to the decreased sample size. In the observation made by Acharya $\mathrm{S} \mathrm{K}$ et al. ${ }^{10} 83.2 \%$ mortality is seen in patients above 40 yrs. The prognosis of hepatitis $A$ is dependent on the age of patient. Young children less than 5 yrs. of age are usually asymptomatic, while most elder children and adults develop symptoms with jaundice and high levels of serum aminotransferase ${ }^{11}$. Recent studies revealed the seroprevalence of anti-HAV is less than $50 \%$ in adult population of $20 \mathrm{yrs}$. to $40 \mathrm{yrs}^{12}$ In this study, the median age of the patients was $23.6 \pm 8.3$, and substantial numbers of patients were below $40 \mathrm{yr}$. We compared the severity of hepatitis between the groups of the patients younger and older than 40 yrs. The clinical manifestations including complications and laboratory data showed that the clinical course in terms of hepatic dysfunction and renal complication was worse in the group of the patients between 23-32 years. These epidemiologic and clinical results suggest that the change of epidemiologic pattern of hepatitis A in our population may lead to increase the disease burden and increase in healthcare cost.

Presence of alcoholism and bad outcome is closely related. Among alcoholic patients $69.2 \%$ had at least one complication with a statistically significant $P$ value of 0.003 . Most common complication noted was fulminant hepatic failure followed by acute pancreatitis.

NSAID intake also had a significant relation with adverse outcome ( $p$ 0.015) and among patients who took NSAID $54.5 \%$ had complications compared to non NSAID group, who had a complication rate of $26.9 \%$. Most common complication noted in NSAID group was fulminant hepatic failure with symptomatic bleeding.

$35 \%$ of the patients had abnormal coagulation profile in the form of PT with INR $>1.5$. Of these $6 \%$ patients had symptomatic bleeding in the form of gastrointestinal and cutaneous bleeding manifestations. As the PTINR value increases, the rate of complications and adverse outcome also increases $(\mathrm{P}=0.009)$. There was no statistical correlation between WBC count and adverse outcome $(\mathrm{P}=0.625)$ and even though $32 \%$ of the patients had thrombocytopenia, no significant relation was found between platelet count and adverse outcome $(\mathrm{P}=0.114)$.

Regarding SGPT value and outcome, 41\% peak SGPT values was within 2001-4000, 32\% within 4001-8000, 17\% within 1001-2000, $6 \%$ within $501-1000,2 \%$ below $<500$ and $2 \%>8000$ IU. Maximum value of SGPT observed was 14000 IU and minimum value was 350 IU. No significant correlation was found between SGPT value and adverse outcome $(\mathrm{P}=0.357)$.

Intake of indigenous medication was found to be associated with adverse outcome and it was associated with 
development of cholestatic hepatitis. Out of 100 patients, 25 had taken indigenous medication for the treatment of hepatitis A. It was in powder and tablet form and content of the medication was not known. Among the patients who took indigenous medication $48 \%$ developed cholestatic hepatitis with significant statistical correlation $(\mathrm{P}<0.001)$.

Out of 100 patients, 12 patients developed fulminant hepatic failure. Out of these 10 patients recovered and 2 patients expired. From recovered patients 9 had grade 1-2 hepatic encephalopathy and one patient had grade 3 hepatic encephalopathy. Advanced stage of hepatic encephalopathy at the time of presentation carries worse prognosis. ${ }^{13}$ Reason for high incidence of fulminant hepatic failure following acute hepatitis A in this study is not clear or it may be due to high prevalence of hepatitis A in our population.

All patients who developed fulminant hepatic failure treated with early initiation of broad spectrum antibiotics, bowel sterilization, prophylactic fresh frozen plasma transfusion and branched chain amino acid therapy.

\section{CONCLUSION}

1. More than $50 \%$ of the patients were belonging to younger age group, indicating that North Kerala is moderately endemic for hepatitis A.

2. Symptomatic hepatitis A in adulthood occurs frequently in North Kerala, and the changing epidemiologic pattern of the disease may increase disease severity and incidence of complications.

3. Hepatitis A may rarely present as long duration fever.

4. Atypical manifestations are rather common in Hepatitis A (most common being thrombocytopenia).

5. Prior NSAID \& alcohol intake is associated with adverse outcome.

6. Use of indigenous medication is strongly correlating with development of cholestatic hepatitis.

7. Reduced liver span \& INR value has significant association with adverse outcome.

8. There is increased risk of complications with high peak bilirubin level.

9. There is no significant correlation between incidence of complications and SGPT level.

\section{REFERENCES}

[1] Feinstone SM, Kapikian AZ, Purceli RH. Hepatitis A: detection by immune electron microscopy of a viruslike antigen associated with acute illness. Science 1973;182(4116):1026-8.
[2] Gust ID. Epidemiological patterns of hepatitis A in different parts of the world. Vaccine 1992;10(Suppl 1): S56-S8.

[3] Schiff ER. Atypical clinical manifestations of hepatitis A. Vaccine 1992;10 (Suppl 1):S18-S20.

[4] Tong MJ, el-Farra NS, Grew MI. Clinical manifestations of hepatitis A: recent experience in a community teaching hospital. J Infect Dis 1995;171(Suppl 1):S15S8.

[5] Koff RS. Clinical manifestations and diagnosis of hepatitis A virus infection. Vaccine 1992;10(Suppl 1):S15-S7.

[6] Shouval D, Ashur Y, Adler R, et al. Safety, tolerability and immunogenicity of an inactivated hepatitis A vaccine: effects of single and booster injections and comparison to administration of immune globulin. J Hepatol 1993;18(Suppl 2):S32-S7.

[7] Kwon SY, Park SH, Yeon JE, et al. Clinical characteristics and outcomes of acute hepatitis A in Korea: A nationwide multicenter study. Journal of Korean Medical Science 2014;29(2):248-53.

[8] Jung YM, Park SJ, Kim JS, et al. Atypical manifestations of hepatitis A infection: a prospective, multicenter study in Korea. J Med Virol 2010;82(8):1318-26.

[9] Shenoy R, Nair S, Kamath N. Thrombocytopenia in hepatitis A--an atypical presentation. J Trop Pediatr 2004;50(4):241-2.

[10] Acharya SK, Dasarathy S, Kumer TL, et al. Fulminant hepatitis in a tropical population: clinical course, cause and early predictors of outcome. Hepatology 1996;23(6):1448-55.

[11] Hadler SC, Webster HM, Erben JJ, et al. Hepatitis A in day-care centers. A community-wide assessment. N Engl J Med 1980;302(22):1222-7.

[12] Sohn YM, Rho HO, Park MS, et al. The changing epidemiology of hepatitis $\mathrm{A}$ in children and the consideration of active immunization in Korea. Yonsei Med J 2000;41(1):34-9.

[13] Rezende G, Roque-Afonso AM, Samuel D, et al. Viral and clinical factors associated with fulminant course of hepatitis A infection. Hepatology 2003;38(3):613-8. 